\title{
Opportunities for floating closed containment systems for fish farming
}

\begin{abstract}
While wild fish stocks are depleting due to over fishing, the fish food industry is trying to keep up with the increasing demand. Concerns are increasing about the environmental impact of open net cages on wild ecosystems since open net cages rely entirely on natural ecological resources of the surrounding water body. The only way to minimize or even exclude the environmental impact of sea-based aquaculture is to make use of closed containment systems where there is minimal contact between the rearing environment and the external environment. This mini-review article presents the current status of seabased closed containment aquaculture and identifies future research topics to realise closed containment aquaculture in near shore and offshore environments.
\end{abstract}

Keywords: floating closed containment systems, sea-based aquaculture, fish farming
Volume 9 Issue 4 - 2020

\author{
CMWang,' JWiegerink,' BT Leow ${ }^{2}$ \\ 'School of Civil Engineering, The University of Queensland, \\ Australia \\ ${ }^{2}$ Founder \& CEO,Aquaculture Centre of Excellence Pte. Ltd., 32 \\ Netheravon Road, Singapore 508508
}

Correspondence: JWiegerink, School of Civil Engineering, The University of Queensland, St Lucia, Queensland, Australia, Emailj.wiegerink@uq.edu.au

Received: July 19, 2020 | Published: August 20, 2020

\section{Introduction}

There are primarily two types of system that are used for sea-based aquaculture activities: open containment and closed containment systems. Open containment systems rely entirely on natural ecological resources. The three most important functions: correct temperature, oxygen supply and waste removal are all taken care of by the external environment. Hence site selection is of vital importance. Under the influence of increased criticism towards this type of containment in harming the local ecosystems, fish farm operators are starting to move farms from calm protected inshore waters to unprotected offshore sites with abundant pristine water supply as well as sufficient space to disperse the waste. This opens an opportunity for closed containment systems in near shore and offshore waters.

Recirculating Aquaculture Systems (RAS) is a type of closed containment system where water is constantly re-used, and it is mainly applied for fresh water aquaculture on land. Although water is re-used, still major water resources are required for the operation; this can be more than $5 \%$ of the total volume per day. ${ }^{1}$ To create salt water RAS on land, the challenges relating to significant energy consumption and land use need to be resolved., ${ }^{2,3}$ Floating Closed Containment Systems (FCCS) that we know today, generally function as semiclosed systems. Water from the external environment is pumped into the system and can be controlled by different treatment processes depending on the internal environment requirements. The same can be done for the water outflow, to discharge in a responsible way. These types of semi-closed systems benefit from being suspended in the sea. Having an internal water level close to the external water level, reduces operational costs for pumping water in and out to a minimum. Moreover, it allows for a tank design with no restrictions on tank depth. Other benefits of utilizing sea space are: increasing land prices due to an increasing world population and the immunity to seismic activities since floating tanks are base isolated in the sea. Different types of structures have been investigated ${ }^{4}$ and applied in the industry: flexible cages, ${ }^{5,6}$ semi-flexible cages and rigid cages. While flexible cages are made out of tarpaulin, semi-flexible cages are made from low stiffness materials like HPDE (high density polyethylene) or GRP (glass reinforced polymer). Rigid cages are mainly made out of concrete or steel.
The estimated costs for producing nearshore farmed salmon in open-net containments and FCCS are $30.6 \mathrm{NOK} / \mathrm{kg}$ and $37.9 \mathrm{NOK} / \mathrm{kg}$, respectively. ${ }^{7,8}$ Although the cost of production in FCCS compared to traditional open net cages is higher for the salmon industry, FCCS has become more attractive from environmental and sustainability points of view. Currently FCCS are still at its infancy. It is believed that the cost of production can be brought down further by advances in closed containment technology and utilizing economy of scale; thereby making FCCS farmed fish a more economically competitive product.

\section{Opinion}

The authors opine that FCCS will play a more significant role in the very near future in sustainable sea-based aquaculture, in sites where water quality is insufficient and natural ecological processes do not allow for open systems. FCCS is eco-friendly in the sense that it does not pollute the water and in fact cleans the water when discharging treated water. Moreover, it ensures that the water environment satisfies the conditions for healthy growth of fish, meets biosecurity requirements, solves the problem of sea lice, ${ }^{9}$ parasite/ pathogen infections and predators (such as seals, sharks and birds) and accommodates a higher stock density with lower mortality rates.

The main challenge with deploying FCCS in a higher energy external environment is to obtain a calm low energy internal environment suitable for fish farming. ${ }^{10}$ This can be done by:

- Reducing the motions of the floating containment structure by using appropriate structural shapes.

- Applying slosh suppression and slosh damping devices suitable for fish tanks.

- Designing internal flow and tank shape to bring together solid waste particles for collection. ${ }^{11}$

\section{Reducing wave loads on structure}

The hydro mechanical behaviour of a floating structure in waves is governed by its full shape, mass and relative size to the wave. ${ }^{12}$ Given certain wave conditions, the motion response of the structure may be reduced by: 
- Streamlining the hull shape of the floating structure to reduce wave forces acting on the FCCS, or by submergence.

- Increasing the size of the complete structure relative to the size of the waves.

- Increasing the effective mass of the structure, relative to the wave forces, by lining up multiple tanks behind each other.

\section{Application of slosh suppression and slosh damping devices suitable for fish tanks}

Internal fluid motions occur under the influence of external tank excitations. A contained water body with a free surface, like a FCCS, will experience sloshing effects. ${ }^{6,13,14}$ At the free surface, sloshing can be observed as chaotic wave motions which go against the need to create a low energy environment for fish welfare. A common way to reduce sloshing is by installing baffles in the tank. ${ }^{15}$ Baffles constrain fluid motions and play a role in slosh energy dissipation. Another way to reduce sloshing effects is to reduce the size of the free surface. However, a compromise shall be made between the total available free surface for fish to reach for air and the total volume of fluid or total amount of fish in the tank.

Sloshing phenomena exist in a wide variety of applications. Typically, a FCCS has only one filling level, in contrast to fuel tanks for example. This makes it suitable to design one dedicated slosh damping device, optimized for one specific tank. Possible designs will compromise with having a damping system near the free surface where most fluid motions occur. This results in a clean tank without internal structures, resulting in more free-swimming space for fish.

\section{Internal flow and tank shape to bring together solid waste particles for collection}

Waste shall be collected and removed as soon as possible to prevent decomposition into toxic components. ${ }^{1}$ In FCCS solid waste will either remain suspended through the water column or drop down to the bottom of the tank. By introducing an internal fluid flow, solid particles can be concentrated, at these accumulation points solid wastes are removed efficiently. The internal tank shape shall accommodate an internal flow for solid particle collection. ${ }^{16,17}$

\section{Review of commercial floating closed containment systems}

Examples of FCCS that have been built are: The Eco-Ark ${ }^{\circledR}$, Fish GLOBE, Salmon Home \#1, Eco Cage, Preline extended smolts farm, Aquafarm Neptune and FiiZK closed cages. Closed containment systems are mainly being deployed at protected sites with relatively low wave heights and low wave periods. No FCCS have been identified that are designed for conditions with a significant wave height $>2.5 \mathrm{~m}$ and wave periods $>5.4 \mathrm{~s}$. FCCS have control over the internal environment allowing for higher stock densities without compromising on fish health. Below, the aforementioned FCCS are described.

\section{Eco-Ark $^{\circledR}$}

The patented Eco-Ark ${ }^{\circledR}$ as shown in Figure $1^{18}$ is deployed in Singapore waters off Pulau Ubin. The existing Novel Offshore Advanced Hull System (NOAHS) Eco-Ark ${ }^{\circledR}$ has four large tanks of $500 \mathrm{~m}^{3}$ and is about the size of an Olympic swimming pool. It has the capacity to produce $166,000 \mathrm{~kg}$ of barramundi fish annually, and enables sustainable farming out at sea in volumes that are 20 times more than average minimum production levels at traditional coastal farms. This integrated floating platform uses offshore and marine technology, IOT and the influent sea water is filtered and ozonated to oceanic fresh water to cultivate the fish. It has a flow-through water supply system which cleans the water before discharging it safely and responsibly back to the sea. It can be switched to recirculation mode when needed. These technologies mitigate the effects of spread of waste to the sea and algae blooms that threaten both the farm and our sea and offshore sites. She has a roof equipped with BIPV solar panels to supply electricity for the fish farm. She has an upper deck for larviculture and post-harvest work allowing the harvest to be cleaned, processed and vacuum pack for fresh same day distribution. This is to transform fish farming practices to be more productive, use less sea space, shorten the unbroken cold chain, be sustainable and be climateresilient.

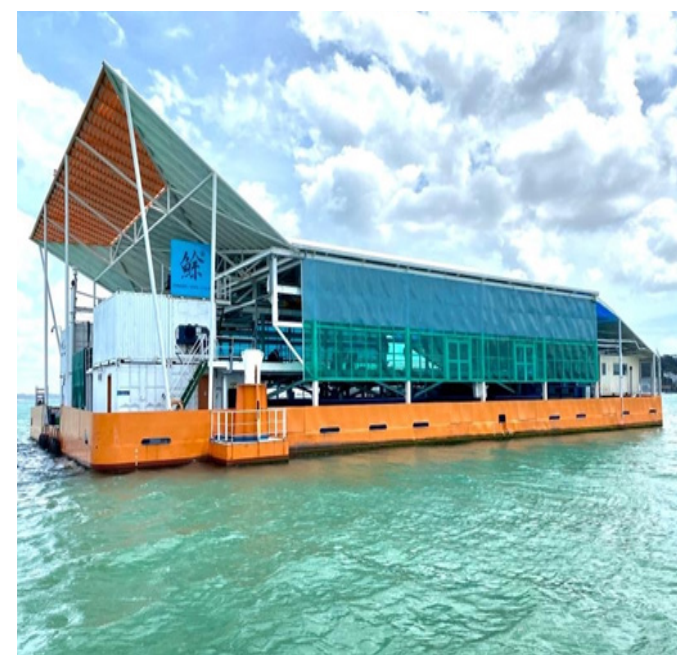

Figure I NOAHS Eco-Ark® (www.ace-sg.com and www.ace-fishmarket. com).

\section{FishGLOBE}

The FishGLOBE is shown in Figure 2. It aims to: reduce the space at sea, minimize the production cost and have minimal negative impact to the environment. The completely enclosed structure has the appearance of an iceberg when operational. The largest model is the FishGLOBE K10 that has a height of $35 \mathrm{~m}$, a volume of $30.000 \mathrm{~m}^{3}$ with a capacity of 2000tons of fish. It is designed to withstand a significant wave height of $2.5 \mathrm{~m}$ and currents up to $1.0 \mathrm{~m} / \mathrm{s}$. Main features of the FishGLOBE are: oxygen supply by feeding in large quantities of water, pumped up by multiple inlet pipes from below the sea lice barrier. Internal currents converge solid waste for efficient removal via one central pipe. The inlet and outlet pipes are integrated with the rest of the structure to increase its stiffness and its rigidity, enabling it to withstand more explosive wave loads. It can be made airtight and pressurized to push out water and gently transport fish out of the tank.

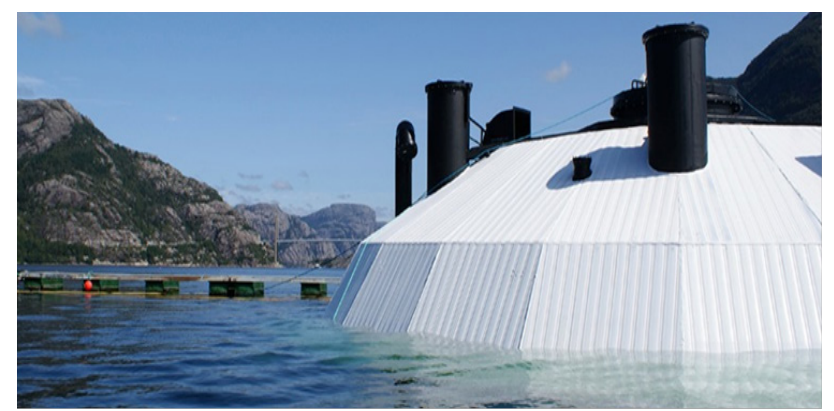

Figure 2 FishGLOBE in operational state (photo courtesy: https://www. fishglobe.no). 


\section{Preline extended smolts farm}

The Preline extended smolt farm, shown in Figure 3, is a semi-rigid raceway type FCCS. This solution is developed by Preline Farming Systems AS. A HDPE tube with a length of $55 \mathrm{~m}$ and a volume of $2200 \mathrm{~m}^{3}$ is suspended horizontally under the water surface. The HDPE tube is netted of at both ends to contain the fish. It accommodates approximately 100k-200k smolts depending on their size. Rectangular cut-outs with extended slot shaped tubes raise beyond the free surface for fish to reach for air. On each end of the HDPE tube two flexible tubes reach down to deeper pristine water below the sea lice barrier. Water is mechanically pumped in via one of the tubes and directly enters the fish containment with a flow rate of approximately $0.15 \mathrm{~m} / \mathrm{s}$. Before water leaves via the other vertical tube, solid particles and dead fish are trapped and collected. Balseiro et al. ${ }^{19}$ reported that Preline is able to produce more robust Atlantic salmon with faster growth rates and lower mortality than standard open cage systems.

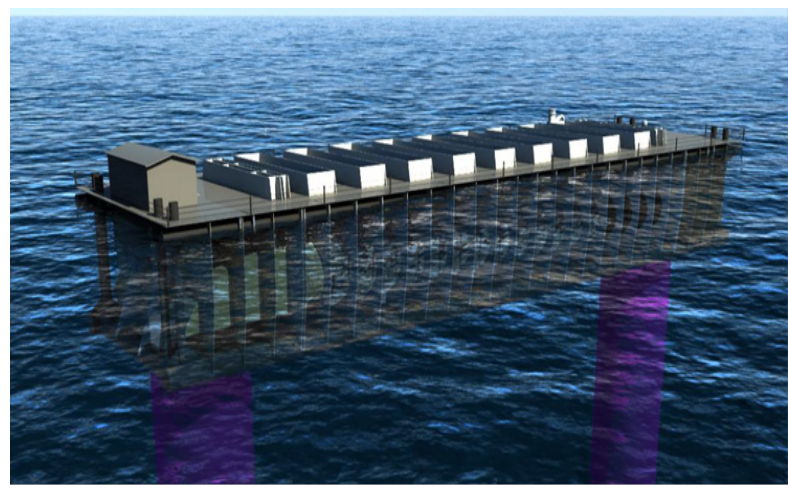

Figure 3 Artist impression of the Preline extended smolts farm, in purple the vertical inlet and outlet tubes are shown (photo courtesy: http://www. preline.no/).

\section{Salmon Home \#I}

The concept of a bucket named as Salmon Home \#1, as shown in Figure $4,{ }^{20}$ is owned by Fish Farming Innovations. This rigid cylindrical FCCS is made from reinforced concrete. It has a tapered bottom. The bucket is the first concrete floating fish farm. The construction consists of steel fibre reinforced concrete on the outside and Styrofoam on the inside to provide buoyancy. The outer ring at the bottom has integrated pretensioned cables to withstand the buoyancy forces working on the bottom of the tank when it floats with less water inside than outside. Near the water surface, a PE pipe is installed for extra buoyancy and stability. The total internal water volume is $1000 \mathrm{~m}^{3}$.

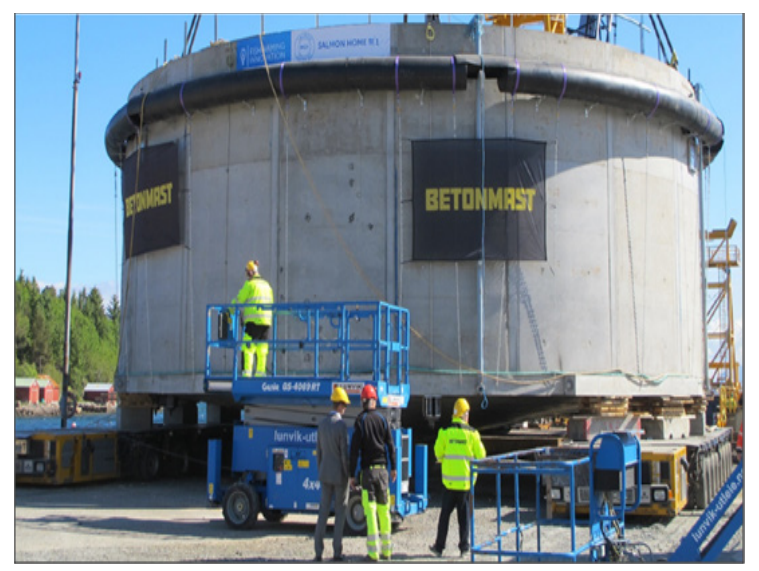

Figure 4 Salmon Home \#I (photo courtesy:Tor Ole Olsen).

\section{Eco Cage}

The Eco Cage, shown in Figure 5, is developed by Ecomerden AS. It is a flexible cylindrical shaped FCCS with a tapered bottom that makes use of a heavy-duty flexible wall. The flexible wall is supported by a rigid metal collar. In order to keep the flexible bag in shape, the internal water has a water head of roughly $8 \mathrm{~cm}$ compared to the outside water level. Within the closed containment, a net is suspended where the fish are kept in. The cages come in different sizes, the largest model that is currently developed has a volume of $30.000 \mathrm{~m}^{3}$. Water from below the containment is pumped up and utilized, to minimize sea lice exposure. An internal current flow is introduced, to keep the post smolts salmon in good condition and to converge waste for collection. The cage is designed to withstand a significant wave height of $2.5 \mathrm{~m}$ and a wave period up to $5.4 \mathrm{~s}$. Field tests have reported an impressive fish survival rate of $99 \%$.

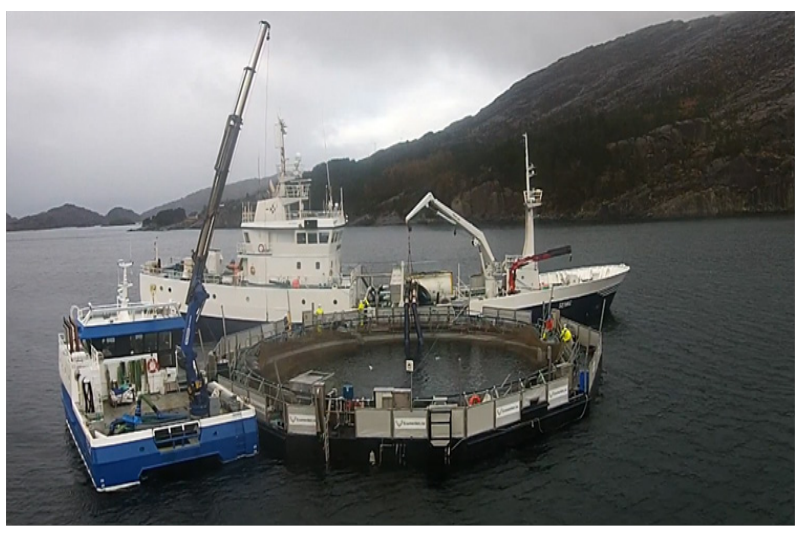

Figure 5 The Eco Cage (photo courtesy: https://www.ecomerden.com/).

\section{Aquafarm Neptune}

The Aquafarm Netpune is a concept developed by Aquafarm Equipment AS in Norway, intended for salmon production, see Figure 6. Aquafarm reports that closed containment systems give many advantages; healthier fish, improved economy, a safe working environment, organic waste utilized as a resource and optimized water quality. The increased fish health has resulted in an extremely low mortality rate off less than $0.5 \%$. The Neptune 3 is a floating cylindrical shaped rigid tank with a tapered bottom for waste collection. The construction consists of GRP (glass fibre reinforces plastic) with steel reinforcements, the cage consists of several elements bolted together. Water is pumped up from a depth of $25-40 \mathrm{~m}$ via 8 inlet pipes. Before it enters the tank, it is filtered, oxygenated and UV treated. The Neptune 3 has an inside diameter of $40 \mathrm{~m}$ with a tank depth of $22 \mathrm{~m}$ enclosing $21.000 \mathrm{~m}^{3}$ of water. The tank is designed to withstand severe storm conditions with winds up to $30 \mathrm{~m} / \mathrm{s}$, currents up to $1 \mathrm{~m} / \mathrm{s}$ and a significant wave height of $2.0 \mathrm{~m}$.

\section{FiiZK closed cages}

The company FiiZK AS, previously known as Botngaard systems, is specialized in developing and delivering flexible tarp based closed cages to the aquaculture industry. Figure 7 shows an impression of the cage. It has been delivered in different volumes ranging from $2.500 \mathrm{~m}^{3}$ up to $10.400 \mathrm{~m}^{3}$.The heavy-duty PVC tarp-based enclosure isolates the internal environment. Water is pumped into the containment via 4 independent intake tubes. The shape is maintained by keeping an internal pressure head and the 16-sided floating steel collar which also provides additional buoyancy. The system is equipped with sensors to constantly monitor the internal environment. Waste is collected at the 
bottom of the containment where it is removed. The largest developed containment system, with a volume of $10.400 \mathrm{~m}^{3}$ has a diameter of $160 \mathrm{~m}$ and is certified for sites with a significant wave height up to $2.0 \mathrm{~m}$ and current velocities of up to $0.7 \mathrm{~m} / \mathrm{s}$. A field trial performed by Cermaq Norway has showed better fish growth and minimal sea lice exposure when compared to surrounding open-net cages.

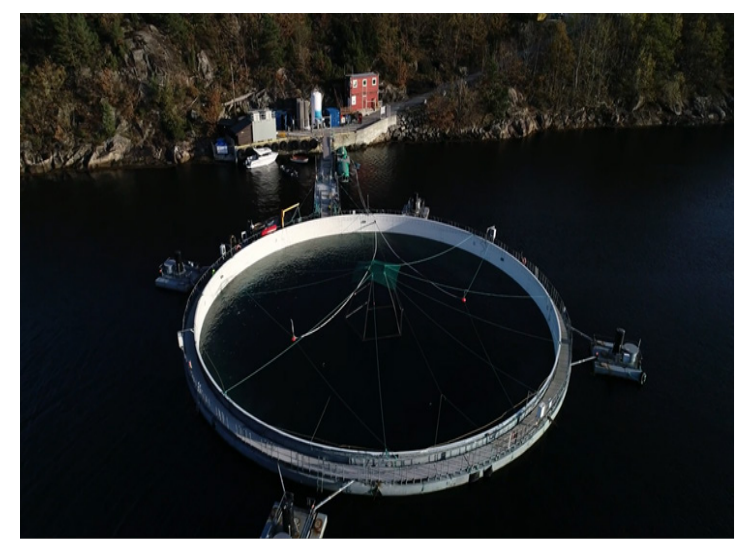

Figure 6 The Neptune (photo courtesy:https://aquafarm.no/).

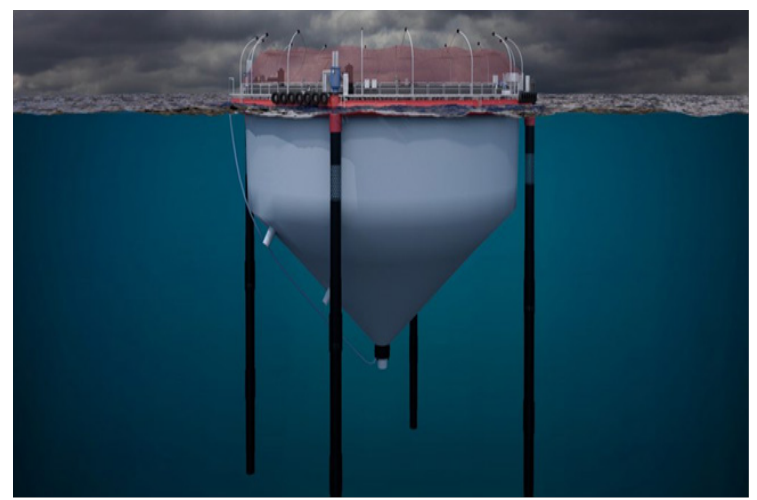

Figure 7 Developed concept of FiiZK (image: https://fiizk.com/en/product/ closed-cage/).

\section{Closed containment systems under development}

Many FCCS concepts have been proposed and are currently in development. Three are discussed in this section that are designed for the salmon industry: The Egg, Stadion Laks and Marine Donut. Figure 8 shows an artist impression of these concepts.
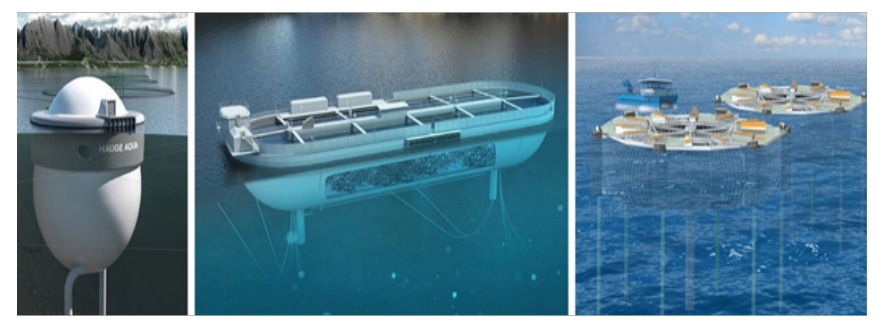

Figure 8 Impression of FCCS under development, The Egg (left, https:// haugeaqua.com/), Stadion Laks (centre, https://stadionlaks.no/) and Marine Donut (right, https://eng.opd.no/hdpe-solutions/projects/marine-donut-anew-technology-for-closed-fish-farming/).

The Egg is being developed by Hauge Aqua which is a company in Norway. It is a fully enclosed egg like structure, made out of composite sandwich that is submerged for $90 \%$. Water is pumped from below the structure via inlet tubes. The water is treated before it enters and leaves the tank.

Stadion Laks has the appearance of a floating bathtub. It is a slot shaped concrete structure with an internal volume of $34.000 \mathrm{~m}^{3}$, where water is circulated. The water intake is located $20 \mathrm{~m}$ below the free surface to avoid sealice.

Marine Donut is developed by Mowi. The technology is owned by OPD systems. It consists of a HDPE (High Density Polyethylene) tube that is configured as a donut shape with an overall diameter of $54.5 \mathrm{~m}$. It is designed to withstand a significant wave height of $3 \mathrm{~m}$. The internal volume is $22,000 \mathrm{~m}^{3}$ with a capacity of 1000 tons of biomass. 6 vertical orientated inlet pipes supply fresh water from below the structure.

\section{Concluding remarks}

The authors opine that Floating Closed Containment Systems (FCCS) will play a more significant role in the very near future in sustainable sea-based aquaculture, at sites where water quality is insufficient and natural ecological processes do not allow for open systems. For the application of FCCS in higher energy environments, research topics are suggested relating to wave forces on the structure, sloshing of water within the structure and solid particle collection. Current commercial FCCS are reviewed together with FCCS that are under development. Some farms are certified up to a significant wave height of $2.5 \mathrm{~m}$. So far, FCCS are mainly used in protected waters. The closed containment aquaculture industry addresses multiple benefits of enabling control over the internal environment, like; increased fish growth and production, lower mortality rates and healthier fish.

\section{Acknowledgments and funding}

The authors are grateful to the Australian Research Council for providing the Discovery Project DP190102983 grant and to the Blue Economy CRC for supporting this study on next generation offshore blue water aquaculture.

\section{Conflicts of interest}

The author declares that there is no conflicts of interest.

\section{References}

1. Tidwell JH. Aquaculture Production Systems. Wiley-Blackwell. 2012.

2. State of Salmon Aquaculture Technologies. Government of Canada, 2019.

3. The Evolution of land based atlantic salmon farms. ISFA (International Salmon Farmers Association). 2016.

4. Safe operation of CLOSED aquaculture CAGES in WAVES. SINTEF 2020.

5. Lader P, Fredriksson DW, Volent Z, et al. Wave response of closed flexible bags. J. Offshore Mech. Arct Eng. 2017;139(5)9.

6. Kristiansen D, Lader P, Endresen P, et al. Numerical and Experimental Study on the Seakeeping Behavior of Floating Closed Rigid Fish Cages. In: ASME 2018 37th International Conference on Ocean, Offshore and Arctic Engineering. 2018.

7. Chu YI, Wang CM, Park JC, et al. Review of cage and containment tank designs for offshore fish farming. Aquaculture. 2020;519:734928.

8. TBjørndal,A Tusvik. Økonomisk analyse av alternative produksjonsformer innan oppdrett. SNF Bergen, Norway. 2018. 
9. Nilsen A, Nielsen KV, Biering E, et al. Effective protection against sea lice during the production of Atlantic salmon in floating enclosures. Aquaculture. 2017; 466:41-50.

10. Helling K, Hausmann S, Clarke A, et al. Experimentally Induced Motion Sickness in Fish: Possible Role of the Otolith Organs. Acta Otolaryngol. 2003;123(4):488-492.

11. Cripps SJ, Bergheim A. Solids management and removal for intensive land-based aquaculture production systems. Aquac Eng. 2000;22(1-2): $33-56$.

12. Journée JMJ, Massie WW. Offshore Hydromechanics. 1st edn. Delft University of Technology. 2001.

13. Ibrahim RA. Liquid Sloshing Dynamics: Theory and Applications. Cambridge University Press. 2005;

14. Faltinsen O M, Timokha AN, Sloshing. Cambridge University Press, 2009 .

15. Abrahamson HN. The Dynamic Behaviour of Liquids in Moving Containers, With Applications to Space Vehicle Technology. NASA USA. 1966.
16. Guo H, Ki SJ, Oh S, et al, Numerical simulation of separation process for enhancing fine particle removal in tertiary sedimentation tank mounting adjustable baffle. Chem Eng Sci. 2017;158:21-29.

17. Gorle JMR, Terjesen BF, Holan AB, et al. Qualifying the design of a floating closed-containment fish farm using computational fluid dynamics. Biosyst Eng. 2018;175:63-81,

18. Leow BT, Technology Driven Sustainable Aquaculture for Eco tourism. WCFS2019. Singapore. 2019:209-218.

19. P Balseiro, Øyvind Moe, Ingrid Gamlem, et al., Comparison between Atlantic salmon Salmo salar post-smolts reared in open sea cages and in the Preline raceway semi-closed containment aquaculture system. $J$ Fish Biol. 2018.93(3):567-579.

20. Olsen TO. Fish Farming in Floating Structures. WCFS2019, Singapore. 2019:191-208. 